\title{
The Location of Non-Specific Esterase in Human Lung Macrophages
}

\section{An Ultrastructural Study}

F. Jaubert ${ }^{1}$, J.P. Monnet ${ }^{1}$, C. Danel ${ }^{1}$, J. Chretien ${ }^{2}$, and C. Nezelof ${ }^{1}$

${ }^{1}$ Groupe de Pathologie Pédiatrique U 77, Hôpital Necker, 149, rue de Sèvres, F-75730 Paris Cedex 15, France

${ }^{2}$ Clinique de Pneumophtisiologie, Hôpital Laennec, 42, rue de Sèvres, F-75007 Paris, France

In "Methods" (line 9) the following sentence should be inserted after the words '... for $72 \mathrm{~h}$ at $4^{\circ} \mathrm{C}$ ':

"The pellets were post fixed with 2,5 Osmium tetroxide in $0.045 \mathrm{M}$ cacodylate buffer for $1 \mathrm{~h}$ at $20^{\circ} \mathrm{C}$.

\section{Announcement}

The $V^{\text {th }}$ Congress of the Czechoslovak Society for Histo- and Cytochemistry will be held with international participation in Olomouc/ČSSR from September 16-19, 1979. Further information may be obtained from the president of the society and of the meeting Prof. MUDr. Z. Loida, Dr. Sc., Laboratory of Histochemistry, Medical Faculty, Studničkova 2, CS-12800 Praha 2, ČSSR. 